\title{
Corrosion Inhibition of Polydopamine Nanoparticles on Mild Steel in Hydrochloric Acid Solution
}

\author{
Feng Yang ${ }^{1}$, Xiangyu Li $^{1,2}$, Zhendong Dai ${ }^{2}$, Tong Liu ${ }^{1,2}$, Wenru Zheng ${ }^{2}$,Haichao Zhao ${ }^{2, *}$ \\ Liping Wang, ${ }^{2, *}$ \\ ${ }^{1}$ School of Materials Science and Engineering, Shenyang University of Chemical Technology, Shen \\ Yang, China 110142 \\ ${ }^{2}$ Key Laboratory of Marine Materials and Related Technologies, Zhejiang Key Laboratory of Marine \\ Materials and Protective Technologies, Ningbo Institute of Materials Technology and Engineering, \\ Chinese Academy of Sciences, Ningbo, China 315201. \\ *E-mail: zhaohaichao@nimte.ac.cn, wangliping@nimte.ac.cn
}

doi: $10.20964 / 2017.08 .52$

Received: 16 May 2017 / Accepted: 11 June 2017 / Published: 12 July 2017

The spherical polydopamine (PDA) nanoparticles with a uniform particle size around 230nm were synthesized successfully by self-polymerization of dopamine hydrochloride in Tris-buffer solution. The inhibitor effects of PDA nanopartilces on mild steel in $1 \mathrm{M} \mathrm{HCl}$ were investigated by weight loss, potentiodynamic polarization, electrochemical impedance (EIS), scanning electron microscopy (SEM) and atomic force microscopy (AFM). The results confirmed that PDA nanopartilces adsorbed onto the mild steel surface and efficiently inhibited the corrosion process. The inhibition efficiency of polydopamine inhibitor was up to $86 \%$ at a concentration of $40 \mathrm{~mol} / \mathrm{L}$, and the adsorption obeyed Langmuir adsorption isotherm. Meanwhile, potentiodynamic polarization studies showed that the corrosion inhibitor was a mixed inhibitor. SEM and AFM further confirmed the formation of a protective film on the mild steel surface.

Keywords: Polydopamine, hydrochloric acid solution, mild steel, adsorption, corrosive inhibitor.

\section{$\underline{\text { FULL TEXT }}$}

(C) 2017 The Authors. Published by ESG (www.electrochemsci.org). This article is an open access article distributed under the terms and conditions of the Creative Commons Attribution license (http://creativecommons.org/licenses/by/4.0/). 